\title{
RECOMMENDATIONS FOR DEVELOPMENT OF ONLINE BOOKSTORE IN INDONESIA: A REVIEW FROM WRITER'S PERSPECTIVE
}

\author{
${ }^{1}$ Robertus Nugroho Perwiro Atmojo and ${ }^{2}$ Anggita Dian Cahyani \\ ${ }^{1}$ School of Information Systems, Bina Nusantara University, West Jakarta, Indonesia \\ ${ }^{2}$ Department of Psychology, Bina Nusantara University, West Jakarta, Indonesia
}

Received 2014-03-10; Revised 2014-04-01; Accepted 2014-04-05

\begin{abstract}
One of the problem when buying books via online transaction in Indonesia is the lack of book preview facility. In this situation the phenomenon of "buying a pig in a poke" is very possible to occur. Moreover, the customer feels disapointed when the book she/he purchases is unavailable. The classical reason usually given is the book stock is not available anymore, because it is discontinued from its supplier. Nevertheless, at the time on the display window the book stock may be "in stock" and the customer is enabled to do the ordering and payment process. This study presents some important recommendations which are expected to help online bookstore developers in Indonesia in order to improve the quality of their services.
\end{abstract}

Keywords: Indonesian Online Bookstore, Online Bookstore Development, Online Bookstore Comparison, E-commerce

\section{INTRODUCTION}

Through online bookstore, any type of books can be bought easily. Just search, click and buy; all can be done online. This practice will be more beneficial for urban people because of its easy access from a distance. Farag et al. (2007) found that urban citizens tend to buy books online compared to those who live in suburban. Saving time is the main reason why urban people do the online purchasing more often than the suburbans. This finding leads to the understanding that not all the potential buyer has much time to do "offline" shopping, come to the shop by themselves, do some reviews and buy product on the spot. In other words, not all potential buyers are always able to do in-store shopping activity. Although based on Schultz and Block (2011), they were reported that the decision making process in product buying is highly influenced by in-store shopping activity. Those findings, will be a challenge for online bookstore owner to adapt all the physical bookstore facilities and implementing them on her/his webstore. Gramedia is one of the several interesting example of superlative bookstores in Indonesia, provides product review facility to its customers with a trial book which can be read without any time restriction. Whenever the trial book is not available on display, the customer still can easily ask for a new sealed book to be opened as a trial book by requesting to the book clerks. Those efforts are made in order to maintain and improve the quality of service to its customers. However, the interesting case of Gramedia's high quality services take place on instore shopping activity. The question is, how about the book review process in online bookstore in Indonesia? Figure 1 could be described as the emersion of writer's disappointment about the unavailability of book stock within a certain online transaction time. Where at that time, the bookstore system allows the writer's to do the purchasing and payment process. Whereas, actually the book stock does not really exists in their or in their suppliers repository.

Corresponding Author: Robertus Nugroho Perwiro Atmojo, School of Information Systems, Bina Nusantara University, West Jakarta, Indonesia 


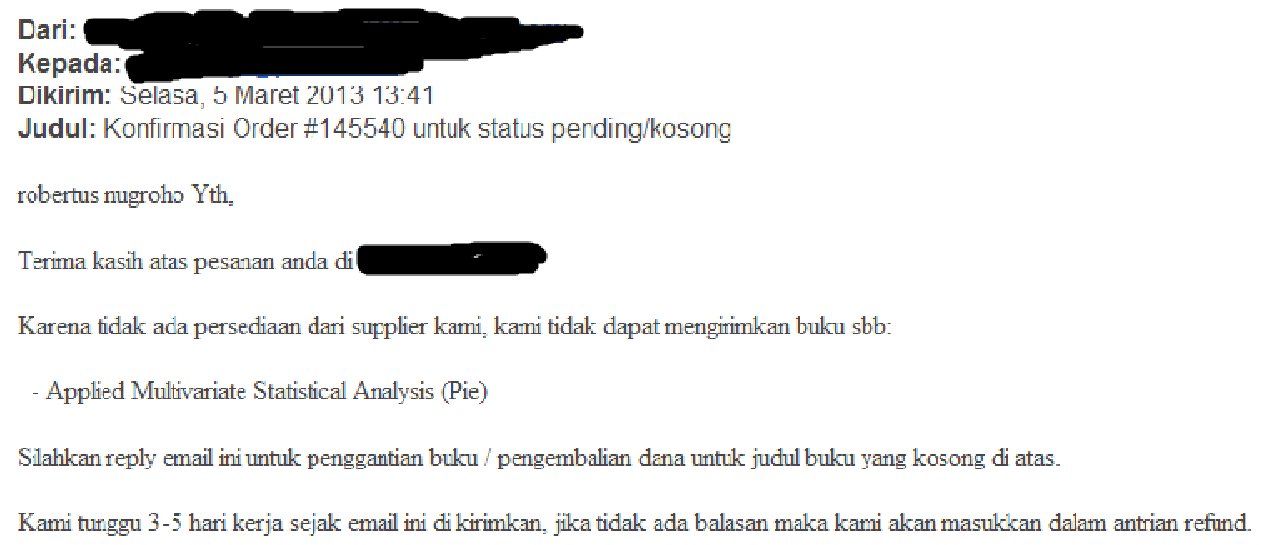

Fig. 1. Email notification from the bookstore informs about the unavailability of book stock from its supplier. The email retrieved on Tuesday, 5th March 2013

And then if the email notification passages on Fig. 1 were translated into English, that will be as follows:

\section{“Dear, Robertus Nugroho.}

Thank you for your order in [bookstore name] In order to the unavailability of stock from our supplier, we cannot do the shipping process of

the book entitled: Applied multivariate statistical analysis (pie).

Please reply this email for book replacement or money refund according to the unavailability of that book titled above.

We will wait for your response within 3-5 work days, since this email has been sent. If there is no response from you, then we will admit it to the refund queue. "

The idea of this review paper, begins from writer's disappointment about online bookstore service quality in Indonesia. Which is, as a consumer in several transactions with the online bookstore. In overall, the writer's did not satisfied towards their services. A set of recommendations from literature reviews and empirical observations to the several world-class online store is expected to help online bookstore developer in Indonesia improve their customer service quality in line with current market needs.

\section{REVIEWS}

In reality, an apple to apple comparison between instore shopping and online shopping can not be simply to obtained which the winner is. Both of them have an excellence value from their loyal consument perspectives. Could be taken as an example, almost of all physical bookstores in Indonesia do not have an internet facility to satisfy its consumer while they need to search a book on the spot. Whereas from the transportation perspectives, Cao (2012) recommends that it is very important for all physical bookstores to provide internet facility for their customer, because it could be simplify the mobilisation process of the customer. So, it is no need for customer to go back to her/his house only to make sure the book they need to buy is suitable. Using the internet, she/he can check the expected book on the spot. Nevertheless physical bookstore has an advantage for book preview process, whereas the online bookstore doesn't.

From our experience to buy book via online transaction, there were several problems that interfere us about the purchase decision. The main problem is, our inability to do the book preview process which make us hesitate to buy or not to buy the book. In online situation, as online shopper our expectation is always having a possibility to do the communication with the sales clerk, in a real time. Nevertheless, almost of online bookstore in Indonesia are quite difficult to contact and very late to answer our question as soon as possible. Our question is, can some of the advantages possessed by the physical bookstore adapted to the online bookstore in Indonesia?

\section{METHOD}

This review paper approach refers to "first people perspective" which has been used by Maswera et al. (2009). This approach has been previously used in giving important recommendation to e-commerce system development in tourism industry of Sub-Saharan Africa. Research objects which were observed in this reseach are online bookstore in 
Indonesia. Compared to the existing giant companies like Barnes and Noble or Amazon.com, the online bookstore in Indonesia is relatively new and, thus, potential to be the focus of current research in terms of technology and consumer research. There are two techniques used in this study: (1) Information gathered based on literature reviews and (2) Information gathered using observational method towards technology features and current customer services on several online store industries.

\section{THE RECOMMENDATION}

There are several recommendations from this study.

\subsection{Product listing Pages Presentation}

Schmutz et al. (2010) found that list presentation has lower user cognitive load than matrix (array) presentation. List presentation is fit to use for showing result from search box, especially for product quantity and price comparison in detail (Fig. 2). Previous study by Honga et al. (2004) supported this finding. User has a tendency to see a product hierarchically and based on Honga et al. (2004) list presentation do has a psychological effect which, thus, supports user to buy a product. Whereas matrix presentation is very appropriate for flash scanning product catalogues (Fig. 3). However, based on writer observation to the current product-listing web e-commerce pages, combination between list presentation and matrix presentation as used in amazon.com or ebay.com is the most appropriate. How comfortable eye movement to fixation wide of productlisting pages is depend on user, thus, will be better if apply combination of both list and matrix presentation.

User would be able to do comparison product test in detail from every angles, both vertically or horizontally.

\subsection{Product Stock Information Transparency}

The observation was resulted from five biggest online bookstores in Indonesia. In Fig. 5 and 6 show that they do not provide information about product availability on their website. From writer's experience, online store that does not show information about product availability could trigger consumer dissatisfaction. The customer expectation is whether they get product as they wish for after clicking "buy" and "pay", based on agreed time. But in reality, most of the time, the product ordered is no longer available or discontinued. Figure $\mathbf{1}$ is a screenshot of email notification received from online bookstore which inform that the book entitled "Applied Multivariate Statistical Analysis (Pie)" has been discontinued from the supplier, while payment has already been done (Fig. 4).
Strategy used by amazon.com can be applied by online bookstore in Indonesia as well. Although the information provided indirectly refers to the product availability numbers, information like "in stock" or "out of stock" (Fig. 7) would reduce permanent consumer disappointment risks to temporary consumer disappointment. Psychologically, "out of stock" information could lead to consumer disappointment, but at least it may lead the consumer still stand expecting for the same product to be "ready stock" soon or may lead them to consider for another product. Consumer disappointment may be caused by lack or dissonance of information, for instance "the product is discontinued", but on the catalog the product is still available and purchasable. That omission could lead to permanent disappointment and loss of customer loyalty (Campo et al., 2004).

\subsection{Real Time Online Support Assistancy}

Previous study about consumer complaint behavior by Jaspera and Waldharta (2013) found that online consumers, complain more than the consumers which do the traditional shopping (in-store shopping). Some of the complaints caused by defect product, the product received is not in line with expectation, or ordered product is discontinued. Elmorshidy (2013) stated that consumer feels more confident in shopping activity when accompanied by another party. Another party might be consumer's significant others (friends, family) or salespeople. Based on Elmorshidy (2013), consumers will appreciate for suggestion and recommendation which is responsive, professional and on the spot before she/he buys a product. Web Embedded Instant Messenger (WEIM) like Yahoo Messenger, therefore, can be used as an effective and efficient tool from either seller and customer perspectives. Seller can show their commitment to give the best service to customer by providing real time assistance using WEIM effectively and efficiently since WEIM is inexpensive. On the other hand, customer would get information needed quickly and directly from the seller. WEIM facility is not only effective tool for customer, but also efficient since customer does not have to send and check email or give a call to seller only to ask about book availability. Figure $\mathbf{8}$ is an example of real time support assistancy that uses WEIM facility from Bhinneka.com.

\subsection{The Online Preview}

To prevent "buying a pig in a poke" when buying a book, Online Book Preview (OBP) like amazon.com's "search inside this book" is highly needed to be applied for every online bookstore."Buying a pig in a poke" is likely to occur and could harm consumers since they 
do not have powerful "veto power" (Gehrig et al., 2007). Consumers tend to get an unexpected product (book) if they do not get opportunity to do product (book) content preview. Without OBP facility, review content by consumers is only possible to do when the book has been purchased and received by themselves. The probability of consumer to get an expected or unexpected content becomes 50:50.

Based on our observation, there are two types of OBP which could be adapted and developed by online bookstore developer. (1). "Search inside this book" facility (Fig. 9) and (2) "my shelf" facility from JSTOR.org (Fig. 10-12). Although amazon.com's "search inside this book" still has limitation on its content pages previewed, it has advantage that consumers do not have to login first to use the facility. It is certainly facilitates the consumer to do a book preview immediately. This is supported by previous study by Tilson et al. (1998) which found that "login first" or "sign up first" requirement before getting interaction into the system is not preferably for some consumers, because it restricts their movement. " $M y$ shelf" facility from JSTOR could be considered to be applied since the facility give an advantage for consumer to do full text content review. Consumers are given a quota amount of reading that is allowed in a certain time frame (e.g., within a month, the consumer is only allowed to review three full text content scientific journal articles). It means that this facility will not be detrimental for the publisher.

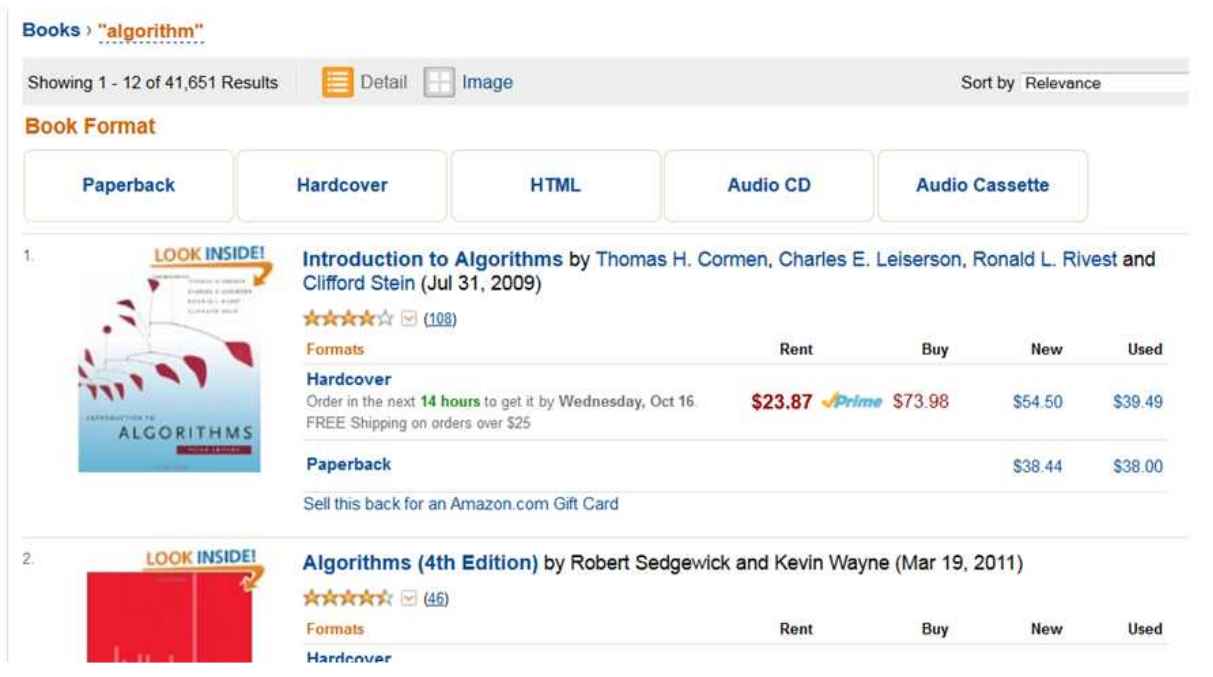

Fig. 2. List presentation of product-listing page from amazon.com

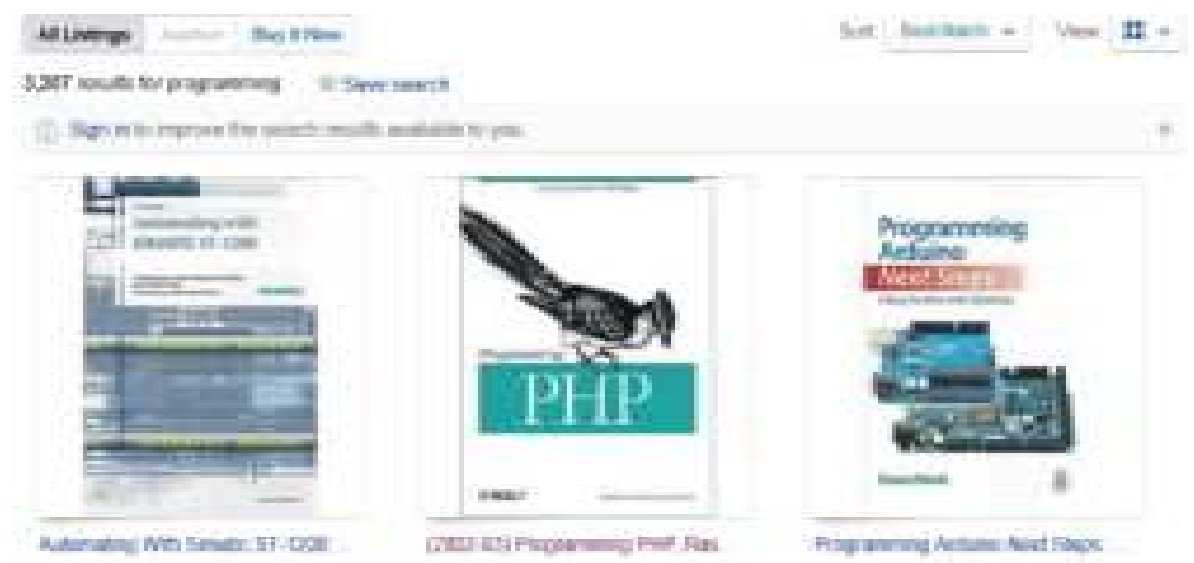

Fig. 3. Matrix presentation of product-listing page from ebay.com 
R.N.P. Atmojo and Anggita Dian Cahyani / Journal of Computer Science 10 (8): 1522-1530, 2014

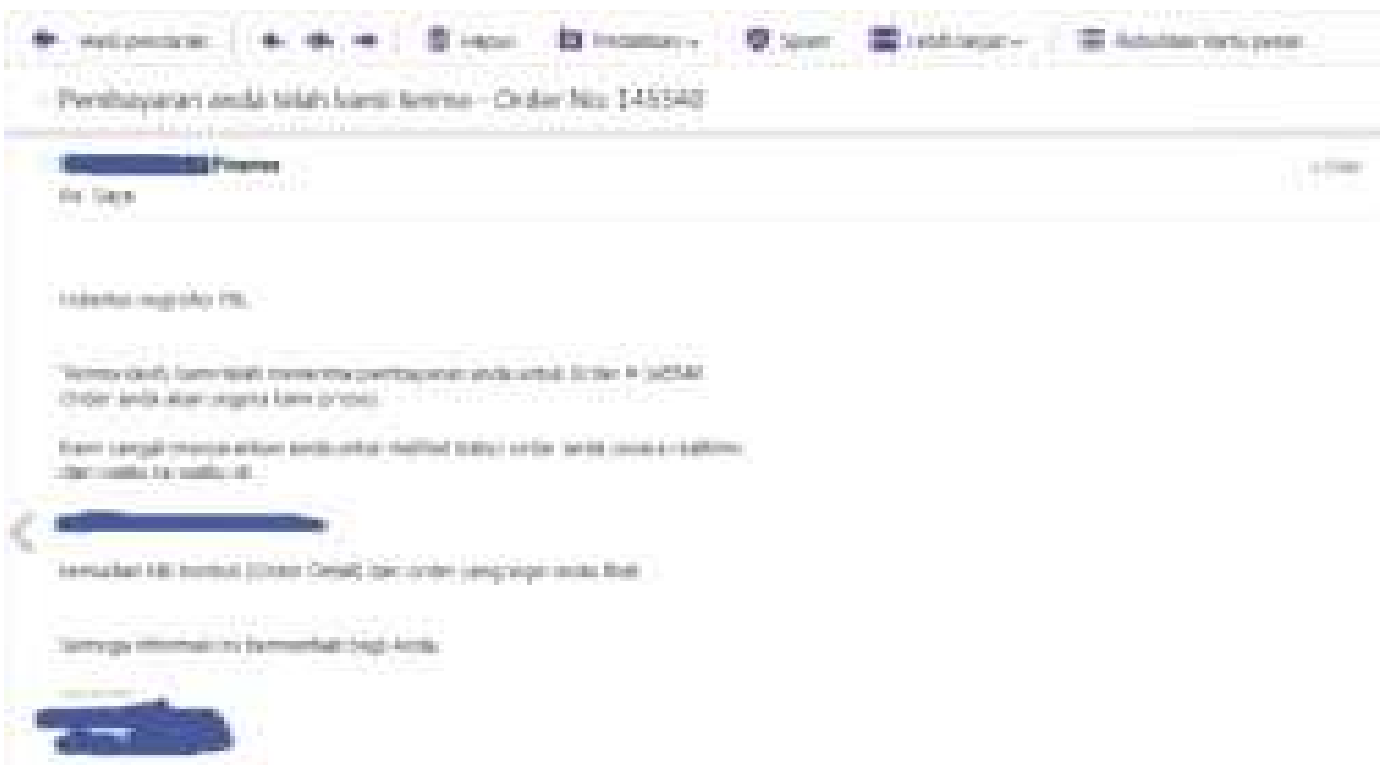

Fig. 4. Information regarding the payment received from online bookstore on Friday, 1st March 2013

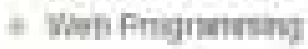

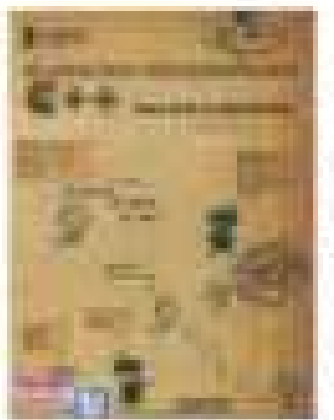

7 Ditaile Bumil

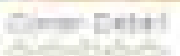

nip- Hith

Itrint is bint

Po 44,000

hith:

Iulu|

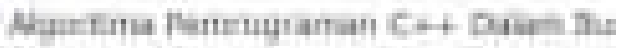

Nn. एथाओ

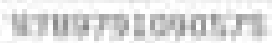

inuilit:

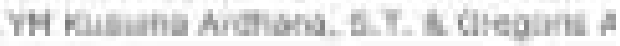

Pisinthii listitar

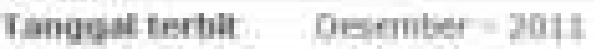

limhli Hht in

Iterat liwhy 757 uा

In nis tomer

fitconr

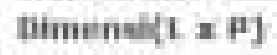

Raltogiri Mrintmaman.

Huntut

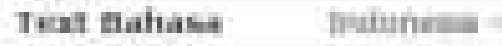

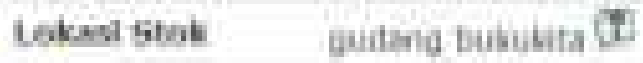

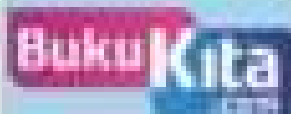

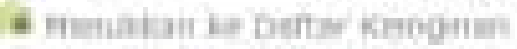

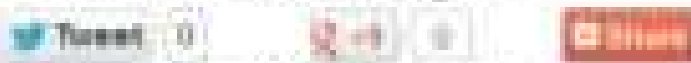

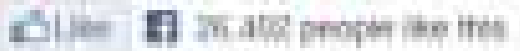

Fig. 5. No information about product stock availability from bukukita.com 


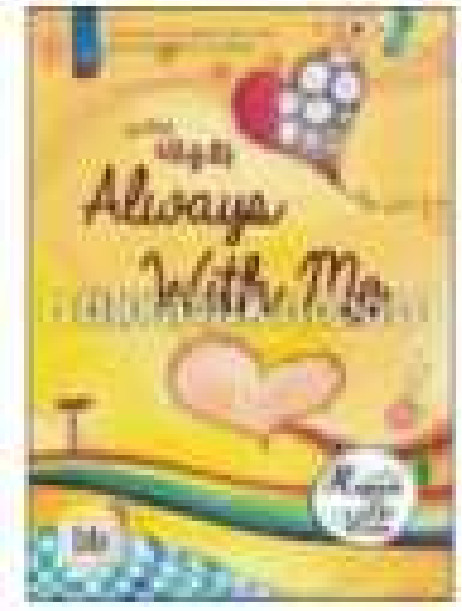

\section{Always With Me}

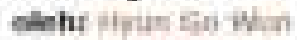

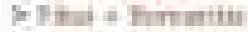

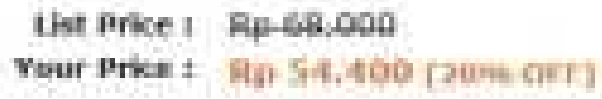

\section{Ainopuis Bukur}

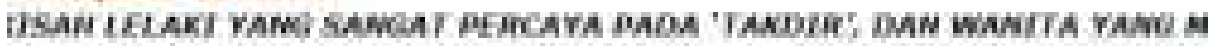

Fig. 6. No information about product stock availability from bukabuku.com

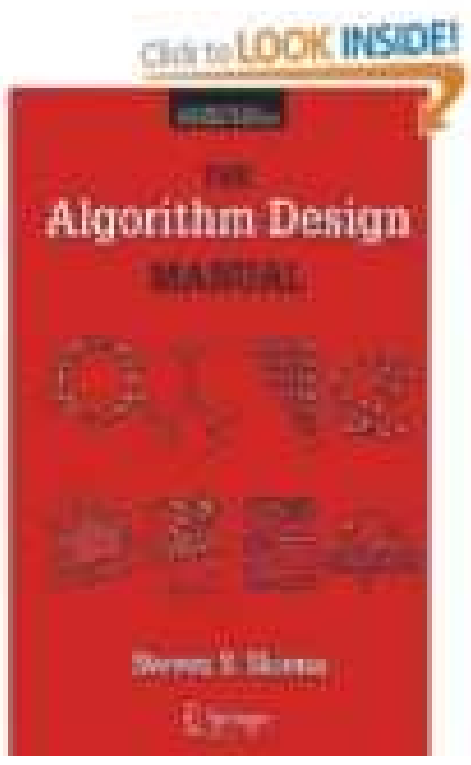

\section{The Algorithm Design Marual |

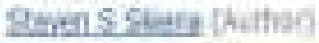

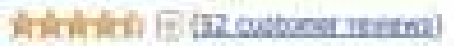

\section{Buy New}

$\$ 53.97$ a FHtE shipping Drtalis

In 5 ock.

Dhp hom and sud by hrasen ich totwounge

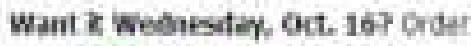

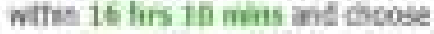

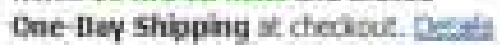

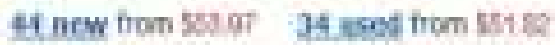

Fig. 7. "in stock" product information from amazon.com 
R.N.P. Atmojo and Anggita Dian Cahyani / Journal of Computer Science 10 (8): 1522-1530, 2014

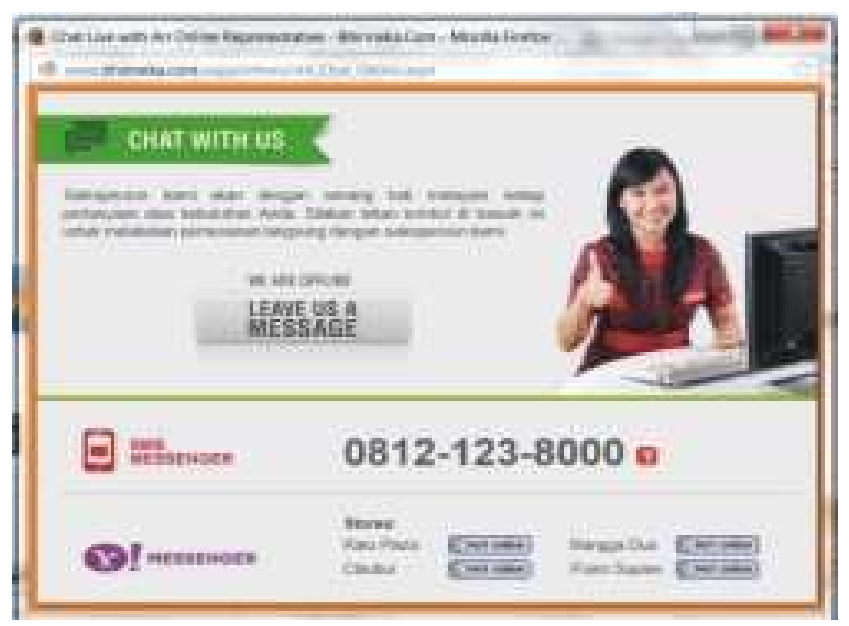

Fig. 8. real time online support assistancy using WEIM facility from Bhinneka.com

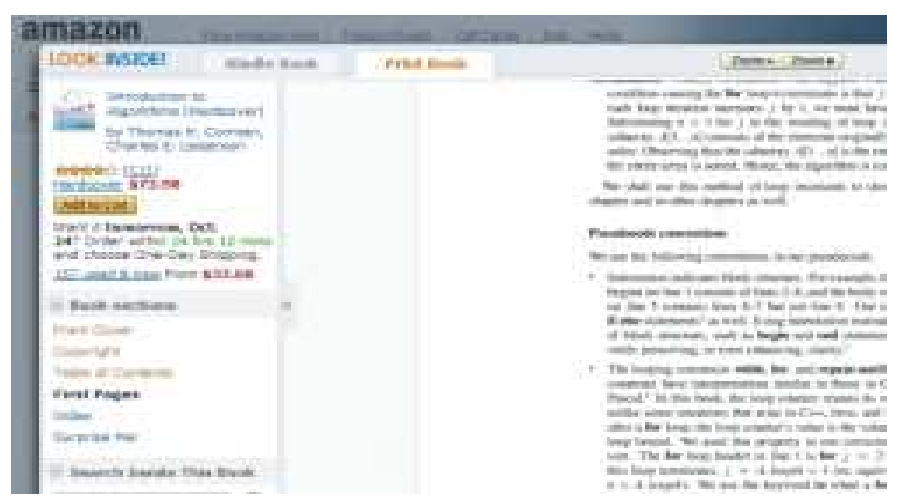

Fig. 9. "search inside this book" facility from amazon.com

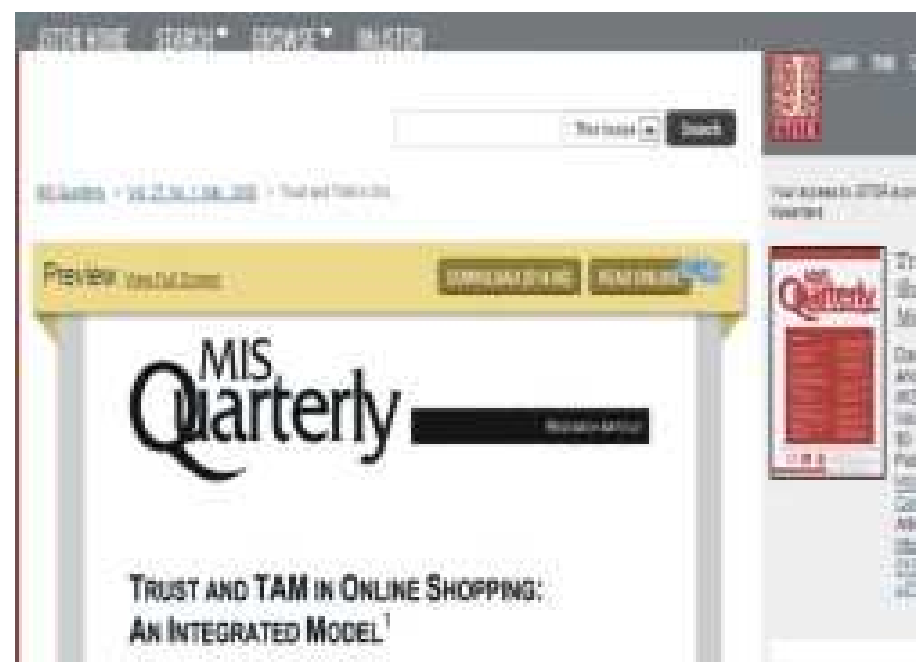

Fig. 10. "my shelf” facility from JSTOR.org (A) 


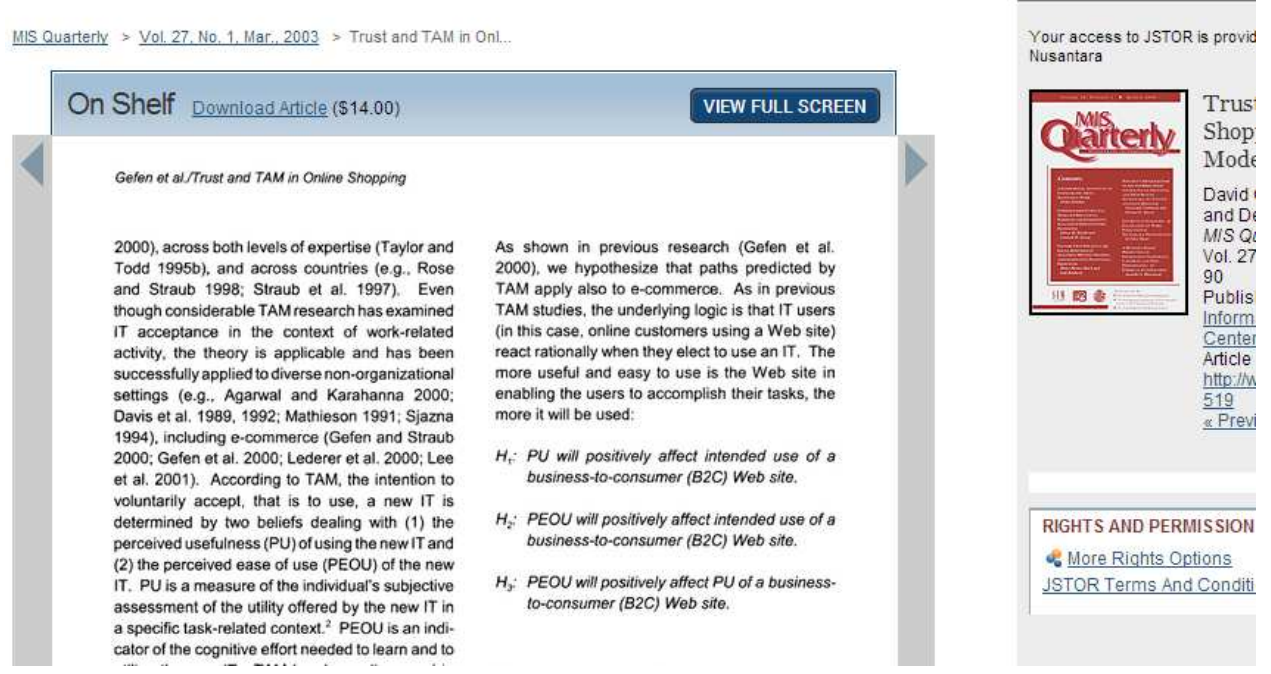

Fig. 11. “my shelf” facility from JSTOR.org (B)

\section{Shelf: 2 Available Spaces}

\section{This is how the shelf works.}

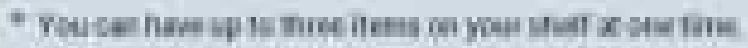

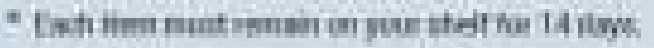

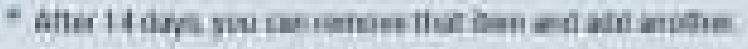

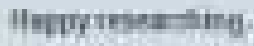

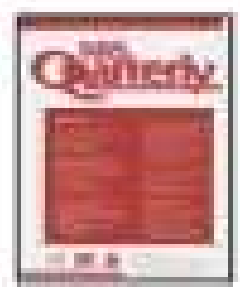

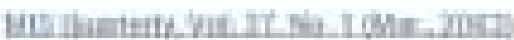

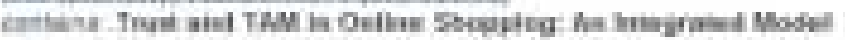

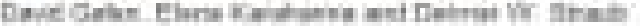

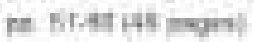

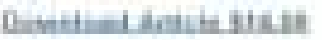 \\ Iiliti \\ IIIA}

Fig. 12. " $m y$ shelf” facility from JSTOR.org (C)

The online preview facility is necessarily to be applied to facilitate potential buyer doing a product review. Previous study by Park et al. (2007) reported that online review quality has a positive influence to consumer purchasing intention towards product. By involving a reviewer on the review process may lead to the communication phenomena namely Word of Mouth (WOM) among the consumers. 


\section{CONCLUSION}

The main purpose of this study is to trigger further study for online bookstore development in Indonesia. Based on four recommendations generated in this study, there are some suggestions for further research topics.

\subsection{Product-Listing Page Presentation}

We assume that product listing presentation that can be switched easily between horizontal position (matrix presentation) and vertical position (list presentation) will be preferable compared to product-listing pages with only horizontal or vertical position. It could be investigated through comparative study about user preferences toward product listing pages.

\subsection{Product-Stock Information Transparency}

Transparency in displaying information of product availability is very important. Consumer will get a guarantee that they will get the product they want. This recommendation could be followed up through study about the influence of product stock information transparency towards consumer purchasing intention.

\subsection{Real Time Online Support Assistancy}

In line with previous study from Elmorshidy (2013) that consumers will highly appreciate for suggestion and recommendation which are responsive, professional and "on the spot" before they buy a product. We assume that every online bookstore needs to provide instant messaging feature to facilitate communication between seller and buyer. Based on this recommendation, further research about how implementation of instant messaging affect consumers purchasing intention needa to be conducted.

\subsection{The Online Preview}

From several trials of buying a book via online transaction in Indonesia, we faced couple of difficulties. One of the difficulties are, we as consumer, always be in a "buying pig in a poke" situation which is always expecting for the good book with the good content too. Without online preview facilities, consumer potentially gets a book which is not as interesting as its cover title. Oftenly, consumers could not rely on ranking method (based on consumer review) or "Best Seller" label. Based on the finding, we assume that every online bookstore is required to provide online preview facility as its commitment of service excellence. This can be a foundation to conduct further research about how people's attitude toward online preview if it is implemented on every online bookstore.

\section{REFERENCES}

Campo, K., E. Gijsbrechts and P. Nisol, 2004. Dynamics in consumer response to product unavailability: Do stock-out reactions signal response to permanent assortment reductions? J. Bus. Res., 57: 834-843.

Cao, X., 2012. The relationships between e-shopping and store shopping in the shopping process of search goods. Trans. Res., 46: 993-1002. DOI: 10.1016/j.tra.2012.04.007

Elmorshidy, A., 2013. Applying the technology acceptance and service quality models to live customer support chat for e-commerce websites. J. Appl. Bus. Res., 29: 589-589.

Farag, S., T. Schwanen, M. Dijst ahnd J. Faber, 2007. Shopping online and/or in-store? A structural equation model of the relationships between eshopping and in-store shopping. Trans. Res., 41: 125-141. DOI: 10.1016/j.tra.2006.02.003

Gehrig, T., W. Güth, V. Levati, R. Levinsky and A. Ockenfels et al., 2007. Buying a pig in a poke: An experimental study of unconditional veto power. J. Econ. Psy., 28: 692-703.

Honga, W., J.Y. Thong and K.Y. Tam, 2004. Designing product listing pages on e-commerce websites: An examination of presentation mode and information format. Int. J. Human-Comput. Studies, 61: 481-503.

Jaspera, C.R. and P. Waldharta, 2013. Internet and distance channel use and European consumer complaint behavior. Int. Rev. Retail, Distrib. Consumer Res., 23: 137-151. DOI: 10.1080/09593969.2012.746717

Maswera, T., J. Edwards and R. Dawson, 2009. Recommendations for e-commerce systems in The tourism industry of sub-saharan Africa. Telematics Inform., 26: 12-19. DOI: 10.1016/j.tele.2007.12.001

Park, D.H., J. Lee and I. Han, 2007. The effect of on-line consumer reviews on consumer purchasing intention: The moderating role of involvement. Int. J. Elec. Commerce, 11: 125-148. DOI: 10.2753/JEC1086-4415110405

Schmutz, P., S.P. Roth, M. Seckler and K. Opwis, 2010. Designing product listing pages--Effects on sales and users' cognitive workload. Int. J. HumanComput. Studies, 68: 423-431.

Schultz, D.E. and M.P. Block, 2011. How U.S. consumers view in-store promotions. J. Bus. Res., 64: 51-54. DOI: 10.1016/j.jbusres.2009.09.021

Tilson, R., J. Dong, S. Martin and E. Kieke, 1998. Factors and principles affecting the usability of four e-commerce sites. 